\section{MICROSTRUCTURAL OBSERVATIONS OF AM DEPOSITED 15-5PH - STELLITE SAMPLE}

JAROSLAV VAVRIK ${ }^{1}$, MILOSLAV BILY ${ }^{2}$, PAVEL SALVETR
MIROSLAV URBANEK
MI, JOSEF HODEK ${ }^{1}$, MICHAL BRAZDA $^{1}$

${ }^{1}$ COMTES FHT a.s., Dobrany, Czech Republic

2Doosan Skoda Power s.r.o., Plzen, Czech Republic DOI : 10.17973/MMSJ.2021_03_2021003

jaroslav.vavrik@comtesfht.cz

AM (Additive Manufacturing) is an increasingly widespread technology in the world. This technique was used in the present work to deposit material on the baseplate in order to find out its ability to repair damaged parts (baseplate material). The material of the baseplate was AKT1TD martensitic steel used in the aviation and energy industry. The steel could suffer from corrosion and erosion, and AM could be the potential method for damaged parts repairing. As a first step, a material similar to the baseplate was deposited. After that, a deposition of a stellite protective layer took place to increase the corrosionerosion resistance. The whole build was observed by $\mathrm{OM}$ (optical microscopy) and SEM (scanning electron microscopy) to evaluate the quality of deposition.

KEYWORDS

Additive Manufacturing, Directed Energy Deposition, Stellite, Microstructure, transitional area

\section{INTRODUCTION}

AM (Additive Manufacturing) is the technology which is day by day more expanding in the world. AM can produce components from a wide selection of materials, from plastics, ceramics, concrete to metals. Metals are usually applied in powder form [Karmakar 2020, Zhang 2019, Ngo 2018 and Jimenez 2019]. Popular AM metals deposition methods are SLM (Selective Laser Melting), DED (Directed Metal Deposition), Binder Jetting, Sheet Lamination. These methods usually have a laser as a source of energy for powder melting and the process takes place in an inert atmosphere, which usually consists of Ar or $\mathrm{N}_{2}$. SLM technique employs mainly the finer fraction of the powder. The powder is poured into the chamber and then spread with a roller. Subsequently, laser melts the powder. DED is one of the popular metal AM method where the powder flows directly to the melt pool along with shield gas. A laser melts the powder then solidifies as the laser travel as per the scanning strategy. The build is created layer by layer. Depositions by DED technique have lower porosity compared to SLM. SLM is a more accurate method and allows the creation of very complex shapes. On the other hand, DED allows deposition directly on the component (possibility to repairs or creation of protective surfaces) in several axes. Both methods find their use in medicine, automotive, energy, aerospace, etc. [Karmakar 2020, Zhang 2019, Ngo 2018 and Jimenez 2019]. DED method can use more powders at once, or extraordinary material combinations such as $\mathrm{Ni}$ with $\mathrm{Ti}$ [Salvetr 2020], Ti6Al4V with TiC, Invar with TiC [Zhang 2019] duplex steels [Brazda 2020] and many others as per the application requirement.

Localized heating and cooling appear during the AM process. It could lead to residual stresses, structural instability and crack formation. Residual stresses in the built structure are important to consider in order to ensure that they remain within the safe limits for the structure. One of the promising methods to decrease residual stress is preheating [Vavrik 2020, Kiran 2020].

As mentioned above, DED enables parts repairing. In this work, AK1TD material as a baseplate was chosen to be repaired. This steel is often used in industry, such as aviation industry, energy industry. It can suffer from erosion-corrosion damage in various environments. The present work structure was to create a build on the baseplate. Firstly, a deposition of a filling material onto the baseplate was printed (because the baseplate's material could be potentially missing in a real situation, so it could be needed to put there similar material with similar properties). Secondly, depositing of protective stellite layers took place to improve corrosion-erosion resistance. Potential weakness could be the transitional area between the baseplate and filling material and the location between filling and stellite.

\section{EXPERIMENT}

Insstek MX-600 machine was used for deposition process. Insstek MX-600 is a metal 3D printer equipped with the DED principle. It has a yttrium fiber laser with maximum power up to $2 \mathrm{~kW}$. The laser melts the powder. The printer has four powder feeders that allow the use of 4 different powders at once during the deposition process. A $3+2$ axes system allows user to deposit material on irregular surfaces.

The baseplate is covered by filling material (similar to the baseplate material), and after that protective layer is deposited. The chemical composition of deposited materials and the baseplate is given in Tab. 1 .

Table 1. Chemical composition of powder and baseplate

\begin{tabular}{|c|c|c|c|c|c|c|c|}
\hline \multirow{2}{*}{$\begin{array}{l}15- \\
5 \mathrm{PH}\end{array}$} & $\begin{array}{c}\mathrm{Fe} \\
{[\%]}\end{array}$ & $\begin{array}{c}\mathrm{Cr} \\
{[\%]}\end{array}$ & $\begin{array}{c}\mathrm{Ni} \\
{[\%]}\end{array}$ & $\begin{array}{c}\mathrm{Cu} \\
{[\%]}\end{array}$ & $\begin{array}{l}\text { Mn } \\
\text { [\%] }\end{array}$ & $\begin{array}{c}\mathrm{Si} \\
{[\%]}\end{array}$ & $\begin{array}{l}\text { C } \\
\text { [\%] }\end{array}$ \\
\hline & bal & 14.7 & 4.3 & 3.5 & 0.6 & 0.5 & 0,02 \\
\hline \multirow{2}{*}{$\begin{array}{l}\text { stellite } \\
\text { CoCr } \\
\text { Mp1 }\end{array}$} & $\begin{array}{l}\text { Co } \\
{[\%]}\end{array}$ & $\begin{array}{c}\mathrm{Cr} \\
{[\%]}\end{array}$ & $\begin{array}{l}\text { Mo } \\
{[\%]}\end{array}$ & $\begin{array}{c}\mathrm{Ni} \\
{[\%]}\end{array}$ & $\begin{array}{c}\mathrm{Fe} \\
{[\%]}\end{array}$ & $\begin{array}{c}\mathrm{C} \\
{[\%]}\end{array}$ & \\
\hline & 64.9 & 28.9 & 6 & 0.02 & 0.03 & $<0.002$ & \\
\hline \multirow{2}{*}{ AK1TD } & $\begin{array}{c}\mathrm{Fe} \\
{[\%]}\end{array}$ & $\begin{array}{c}\mathrm{Cr} \\
{[\%]}\end{array}$ & $\begin{array}{l}\text { Mo } \\
{[\%]}\end{array}$ & $\begin{array}{c}\mathrm{Ni} \\
{[\%]}\end{array}$ & $\begin{array}{c}\mathbf{C} \\
{[\%]}\end{array}$ & $\begin{array}{l}\text { W } \\
{[\%]}\end{array}$ & \\
\hline & bal & 12.1 & 0.4 & 1.7 & 0.12 & 1.8 & \\
\hline
\end{tabular}

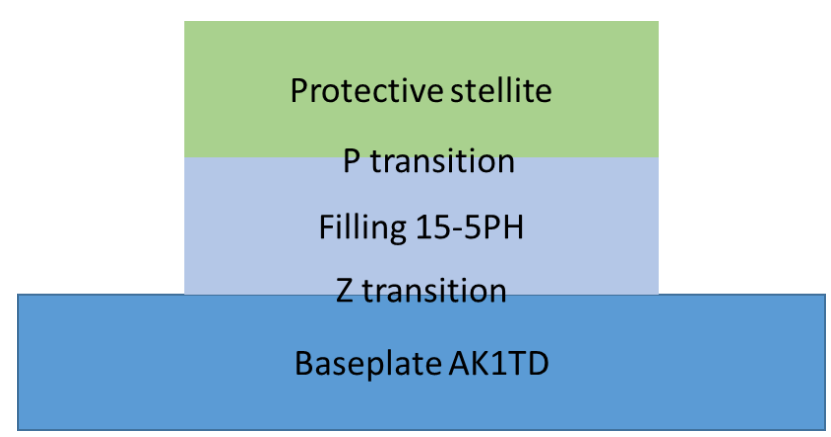

Figure 1. Illustration of the build

Single lines with different laser powers were deposited to determine the appropriate laser power for successful deposition for respective materials. Furthermore, a sample of $20 \mathrm{~mm}$ cube was deposited, where the first half (in height) was deposited by filling material and the second half was protective material, see Fig. 1. The cube was deposited for a detailed study of the microstructure and primarily transition areas were studied using OM and SEM. The microstructure was observed with OM Nikon ECLIPSE MA200 and SEM JEOL IT 500 HR. 
The cube for printing was prepared using Magic Materialize software. The deposition strategy was chosen as CF ZZ, where C refers to "Contour," $F$ to "Fill", and ZZ means "Zig Zag". The starting position of the laser for each layer was shifted by $90^{\circ}$. The hatch distance was $0.5 \mathrm{~mm}$.

\section{RESULTS}

\subsection{SINGLE LINES}
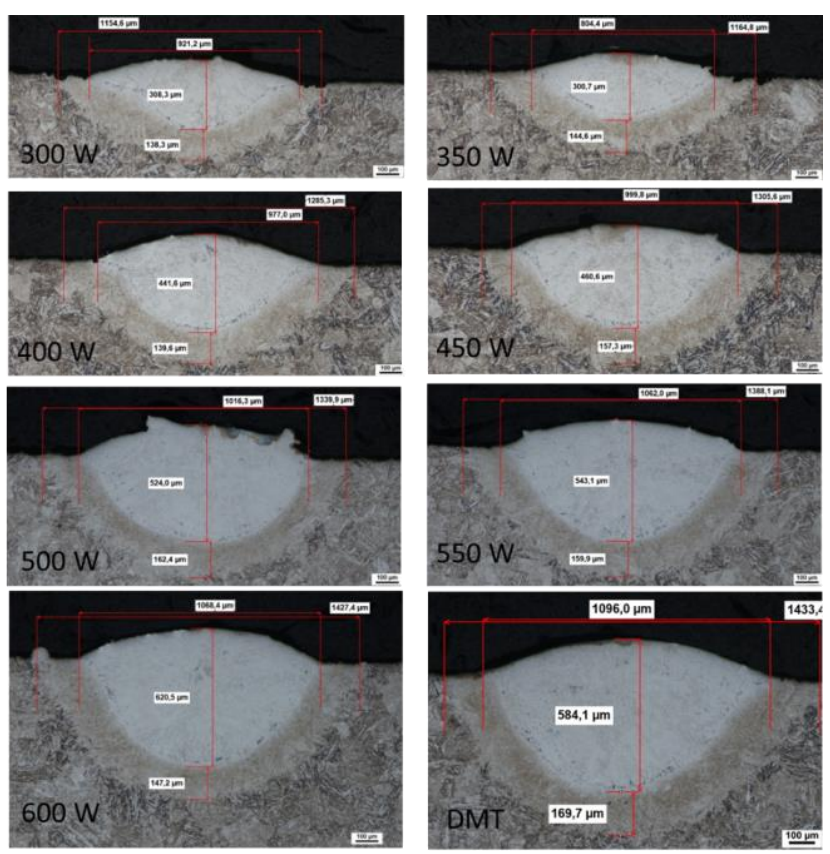

Figure 2. OM Single line of 15-5PH on AK1TD base with different laser powers

Single lines were deposited in order to determine suitable process parameters. These tests consist of varying laser power from $300 \mathrm{~W}$ to $600 \mathrm{~W}$ at $50 \mathrm{~W}$ increment. The size (height, width) of the deposited layer and the HAZ (heat affected zone) are determined, see Fig. 2-3. First, lines (15-5PH) were deposited on a baseplate, see Fig. 2. Then, $2 \mathrm{~mm}$ thick layer of $15-5 \mathrm{PH}$ was deposited on the baseplate and stellite was deposited on 15-5PH layer, see Fig. 3. Images of both depositions reveal the dependence of the increasing height and width of the deposited line on the increasing laser power. Laser power also influences HAZ, see Fig. 2-3. Deposition on the baseplate material shows a smaller HAZ compared to stellite printing on 15-5PH (with the same laser powers). A sample marked as "DMT" was printed with variable power. Power was adjusted during the deposition process to achieve superior quality. The laser power in DMT mode varies depending on the nozzle's distance from the platform and tries to maintain an ideal distance of $9 \mathrm{~mm}$. Thanks to that, an excellent welded layer/line is formed. The laser power in DMT mode ranged between 400-550 W. Images with a constant laser power of 450-550 W appear to be the best-deposited result, evaluated based on the future sample's coherence. The deposition on the material must be coherent without significant defects (pores, inclusions, etc.). Samples with lower laser power are very long and not deep, so the materials' cohesiveness is likely to be less.
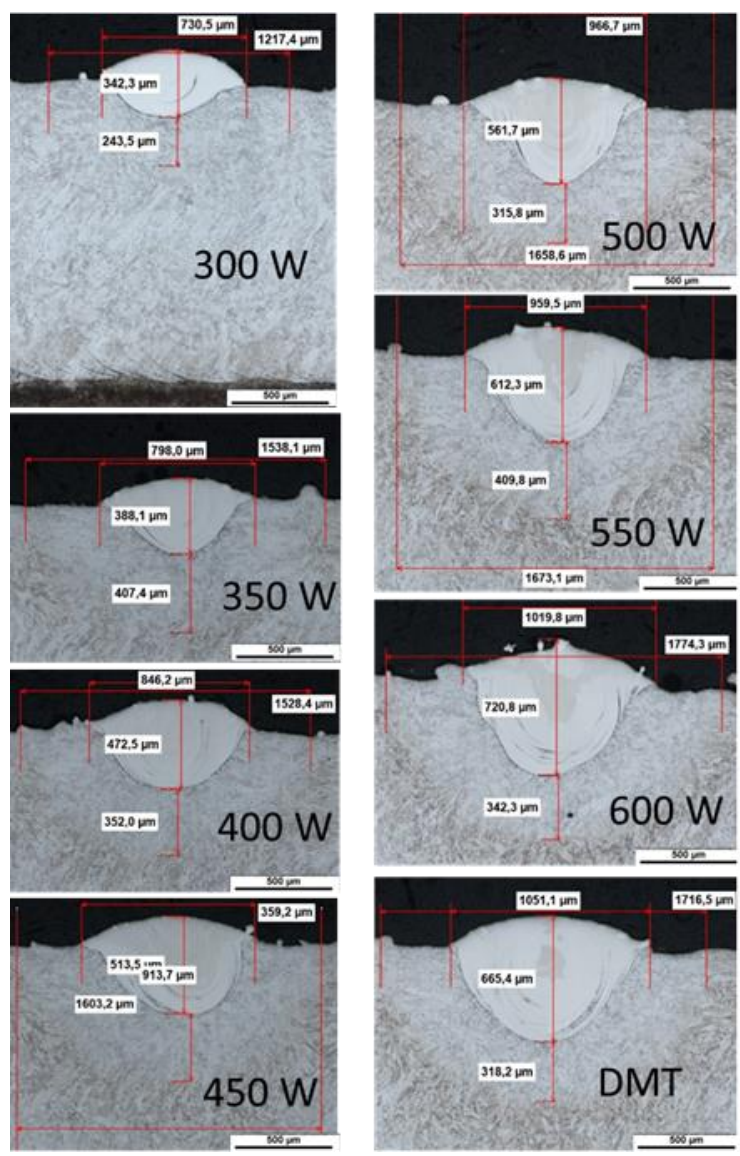

Figure 3. OM Single line of stellite on 15-5PH with different laser powers

\subsection{MICROSTRUCTURE OF THE BASEPLATE}

The baseplate's microstructure, see Fig. 4 A) and B) shows the structure of tempered martensite with carbides present mainly along the boundaries of martensitic needles.

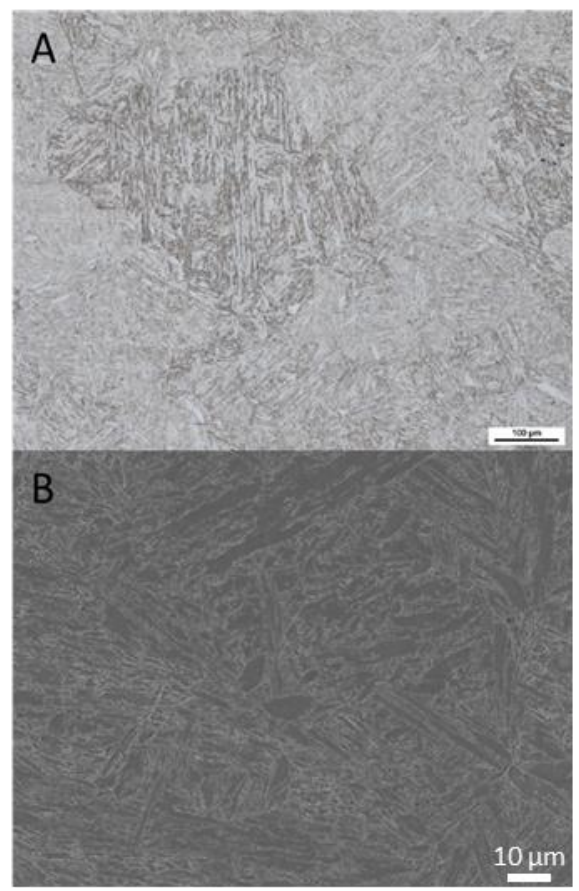

Figure 4. AK1TD baseplate A) OM, B) SEM 


\subsection{MICROSTRUCTURE OF Z TRANSITION}

Transition Z, see Fig. 5 A) and B), shows the interaction of both materials of the first applied layer of filling material $15-5 \mathrm{PH}$ with the baseplate AK1TD. Microscopy observations did not detect inhomogeneities such as pores or inclusions in the transition area. The HAZ is approximately 200-300 $\mu \mathrm{m}$ wide, which is a very low value.

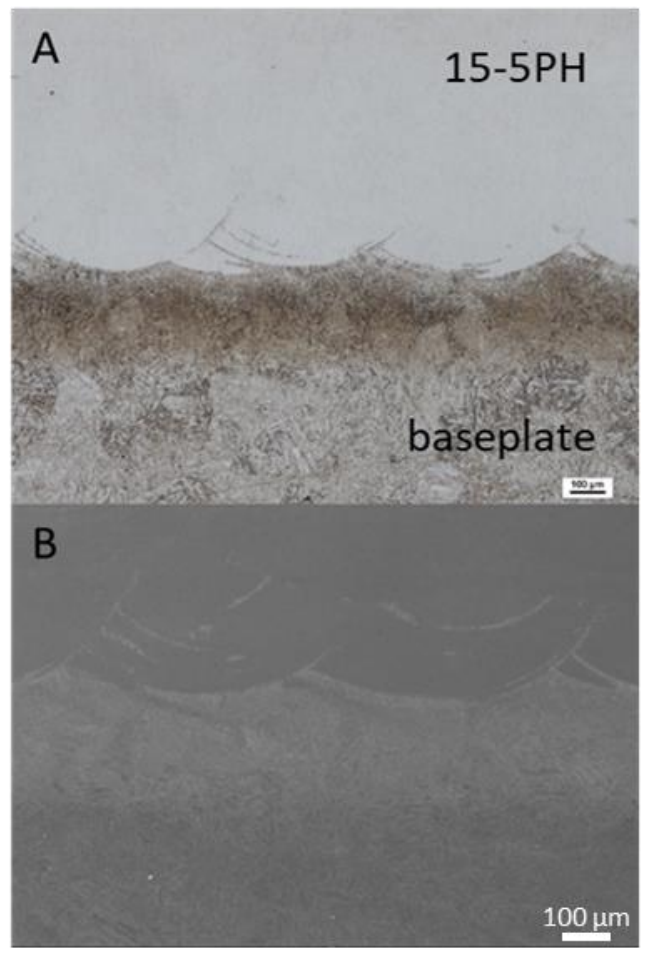

Figure 5. $Z$ transition A) OM, B) SEM

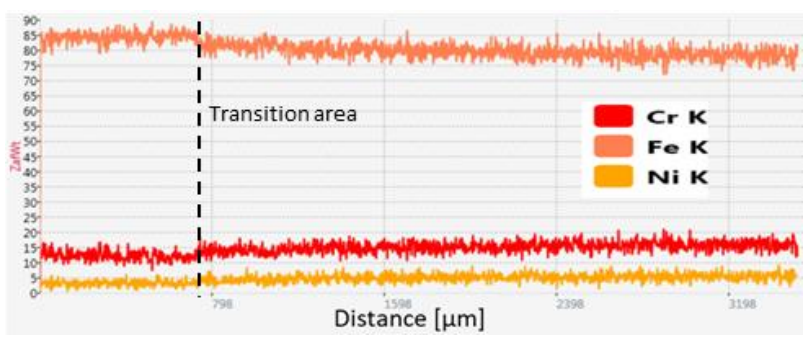

Figure 6. Spectral analysis of the element presence in Z transition area dependence of the element presence on the distance

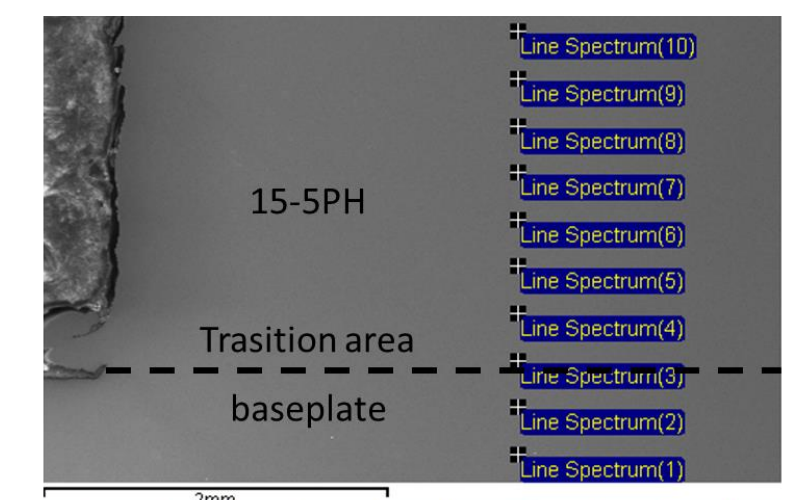

\begin{tabular}{|c|c|c|c|c|c|c|c|c|c|c|}
\hline Elem. & Spot 1 & Spot 2 & Spot 3 & Spot 4 & Spot 5 & Spot 6 & Spot 7 & Spot 8 & Spot 9 & Spot 10 \\
\hline Fe & 83.6 & 83.9 & 77.4 & 76.3 & 75.7 & 76.4 & 75.6 & 76.3 & 76.2 & 75.8 \\
\hline $\mathrm{Cr}$ & 12.2 & 12.5 & 15.1 & 15.4 & 15.4 & 15.5 & 15.3 & 15.3 & 15.1 & 15.2 \\
\hline $\mathrm{Ni}$ & 1.8 & 1.7 & 3.6 & 4.4 & 4.1 & 3.9 & 4.2 & 4.0 & 3.9 & 4.3 \\
\hline $\mathrm{Cu}$ & & & 2.7 & 3.1 & 3.4 & 3.0 & 3.5 & 2.9 & 3.3 & 3.5 \\
\hline $\mathrm{Si}$ & & & 0.7 & 0.4 & 0.6 & 0.5 & 0.8 & 0.6 & 0.6 & 0.6 \\
\hline $\mathrm{Mn}$ & & & 0.5 & 0.4 & 0.8 & 0.7 & 0.6 & 0.9 & 0.9 & 0.6 \\
\hline $\mathbf{M o}$ & 0.5 & 0.3 & & & & & & & & \\
\hline $\mathbf{W}$ & 1.9 & 1.6 & & & & & & & & \\
\hline
\end{tabular}

Figure 7. Spot analysis of elements presence in Z transition area - the table is in wt. \%

Spectral and Spot analyses were performed to obtain information on how or whether the individual layers are mixed, especially in the transition area. Spectral analysis for the element presence, see Fig. 6 , shows the similarity of the filling material with the baseplate material - there are no significant chemical composition changes. However, a slight decrease in the Fe amount can be observed in the base to filling direction. In contrast, the amount of $\mathrm{Cr}$ slowly increases, which corresponds with the chemical composition of the 15-5PH powder. Spectral analysis was supported by spot analysis, see Fig. 7. The spot analysis confirms the spectral outputs. The amounts of $\mathrm{Fe}, \mathrm{Ni}$, and $\mathrm{Cr}$ are relatively constant from point 4 to 10. The amount of $\mathrm{Cu}$ varies in the range of $2.9-3.5 \%$. The 15

$-5 \mathrm{PH}$ powder contains 3.5 wt. \% (information by powder producer). This range (2.9-3.5 wt. \%) may be caused by measurement inaccuracy, the presence of segregation, etc.

\subsection{MICROSTRUCTURE OF FILLING MATERIAL 15-5PH}

The structure of martensitic stainless steel $15-5 \mathrm{PH}$ after DED, see Fig. 8 forms martensitic needles with carbide precipitates. There are well visible local boundaries of the original austenitic grain and meltpools. 


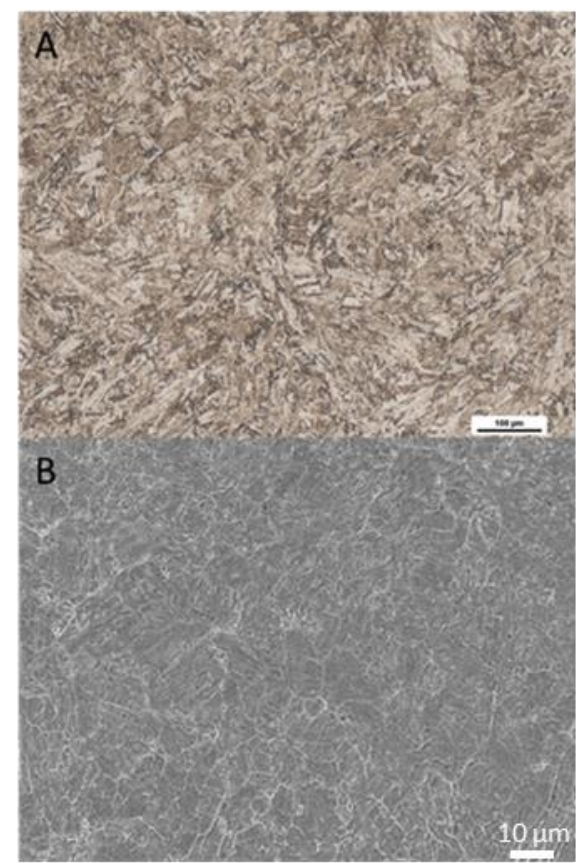

Figure 8. Filling material 15-5PH A) OM, B) SEM

\subsection{MICROSTRUCTURE OF P TRANSITION}

Transition $\mathrm{P}$, see Fig. $9 \mathrm{~A}-\mathrm{C}$ ) is characterized by melt pools penetrating the $15-5 \mathrm{PH}$ steel, thereby mixing both materials. Based on the images, it is possible to estimate the HAZ, which, similarly to the $Z$ transition, is around $300 \mu \mathrm{m}$. Fig. $9 \mathrm{~B}$ ), where stellite was etched (steel is selectively etched in these areas due to its lower corrosion resistance to the etchant) shows the significant transition of stellite with $15-5 \mathrm{PH}$. More precisely, the transition is created by $15-5 \mathrm{PH}$ with a layer containing $15-$ $5 \mathrm{PH}$ and stellite with a layer containing less steel, and then only stellite itself, as evidenced by SEM image, see Fig. 9 C). The microstructural analysis did not detect inclusions or pores in the layers where mixing occurred. Fe mixing can increase the cohesion of the transition area.
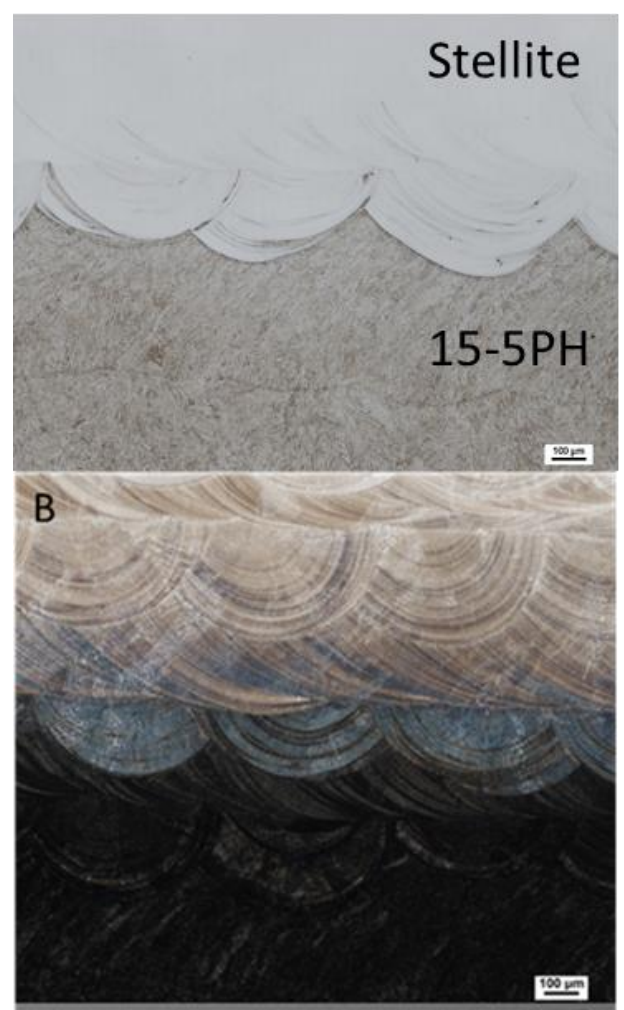

C

$100 \mu \mathrm{m}$

Figure 9. Transition P A) OM steel etching, B) stellite etching, C) SEM

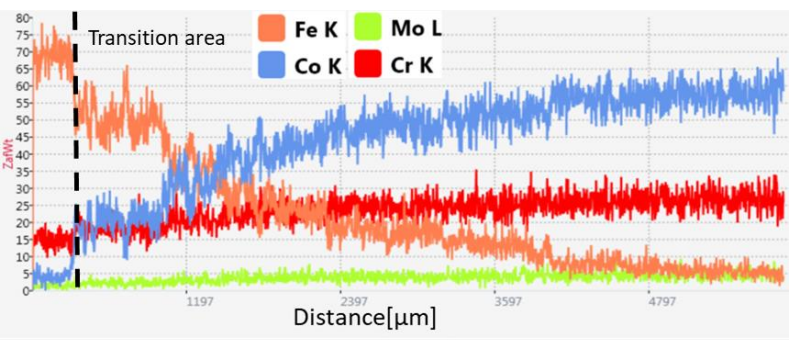

Figure 10. Spectral analysis of the element presence in $\mathrm{P}$ transition area in the direction $15-5 \mathrm{PH} \rightarrow$ stellite

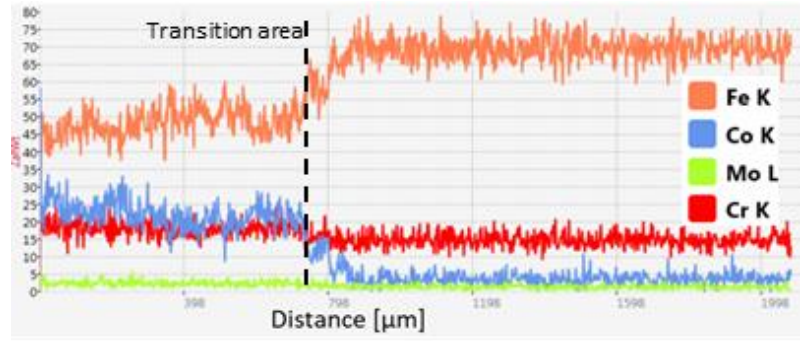

Figure 11. Spectral analysis of the element presence in $\mathrm{P}$ transition area in the direction stellite $\rightarrow 15-5 \mathrm{PH}$ 


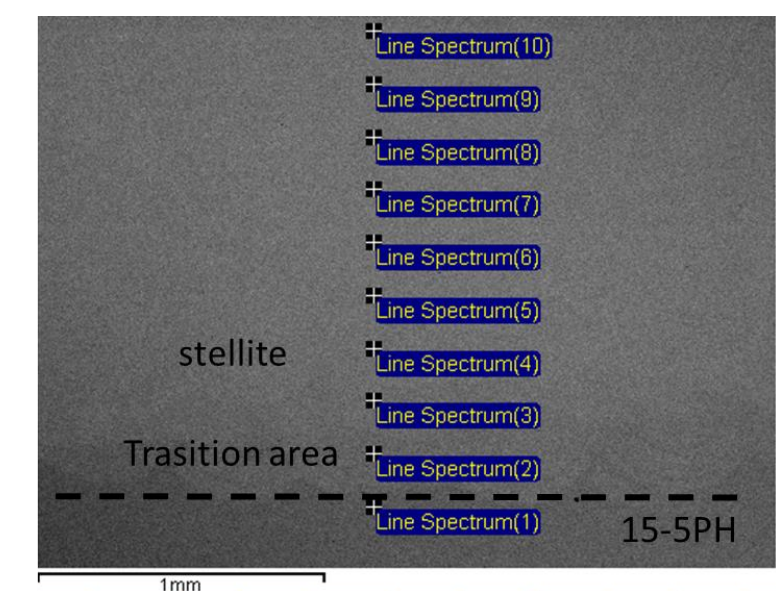

\begin{tabular}{|c|c|c|c|c|c|c|c|c|c|c|}
\hline Elem. & Spot 1 & Spot 2 & Spot 3 & Spot 4 & Spot 5 & Spot 6 & Spot 7 & Spot 8 & Spot 9 & Spot 10 \\
\hline Fe & 74.8 & 57.5 & 33.9 & 23.6 & 17.1 & 11.6 & 11.8 & 6.7 & 6.7 & 5.2 \\
\hline Cr & 15.8 & 19.1 & 22.6 & 25.6 & 26.2 & 27.5 & 26.8 & 27.8 & 28.4 & 29.4 \\
\hline Co & & 16.7 & 35.5 & 43.7 & 51.5 & 54.8 & 55.9 & 59.6 & 59.4 & 59.4 \\
\hline Mo & & & 3.5 & 5.1 & 5.1 & 6.1 & 5.5 & 5.9 & 5.6 & 9.1 \\
\hline Cu & 3.6 & 2.3 & 2.0 & 1.1 & & & & & & \\
\hline Si & 0.8 & 0.3 & & & & & & & & \\
\hline $\mathbf{N i}$ & 4.4 & 3.6 & 2.5 & 0.9 & & & & & & \\
\hline $\mathbf{M n}$ & 0.7 & 0.6 & & & & & & & & \\
\hline
\end{tabular}

Figure 12. Spot analysis of the element presence in $\mathrm{P}$ transition area in the direction of stellite $\rightarrow$ filling $15-5 \mathrm{PH}$ - the table is in wt. \%

Spectral analysis of the element presence was performed, see Fig. 10-11. The mixing of the layers is visible in Fig. 10 The direction towards stellite is characterized by a significant decrease in the Fe amount and a considerable increase in Co amount, while the amount of $\mathrm{Cr}$ does not increase much. The graph shows that $\mathrm{Fe}$ is present in stellite even at a distance of $3 \mathrm{~mm}$ from the transition area, but of course in a minimal amount. The partial melting of the steel layer during the first stellite layer deposition causes its presence. Fe is mixed with stellite, and further mixing occurs when another layer is deposited. Fe at a distance of $2 \mathrm{~mm}$ from the transition in stellite is still present in the amount of about $5 \mathrm{wt}$. \%. The same analysis in the opposite direction (stellite $\rightarrow 15-5 \mathrm{PH}$ ), see Fig. 11, is characterized by the opposite trend - the amount of Fe increases and Co decreases. Steel $15-5 \mathrm{PH}$ is already chemically stable at a distance of one layer $(200 \mu \mathrm{m})$ from the transition (towards 15-5PH), see Fig. 11 and no change in chemical composition was observed. During the first stellite layer printing on $15-5 \mathrm{PH}$, partial mixing of both materials appeared. This happened only in the last layer of $15-5 \mathrm{PH}$. Thus, under the last layer of steel, the steel is unchanged and not affected by stellite (chemically). This fact and Fe presence in stellite is also confirmed by spot analysis, see Fig. 12 and Fig. 13. Mixing of $\mathrm{Fe}$ in stellite layers can be a potential weakness, which could change the stellite protective layer's corrosion-resistant behaviour.

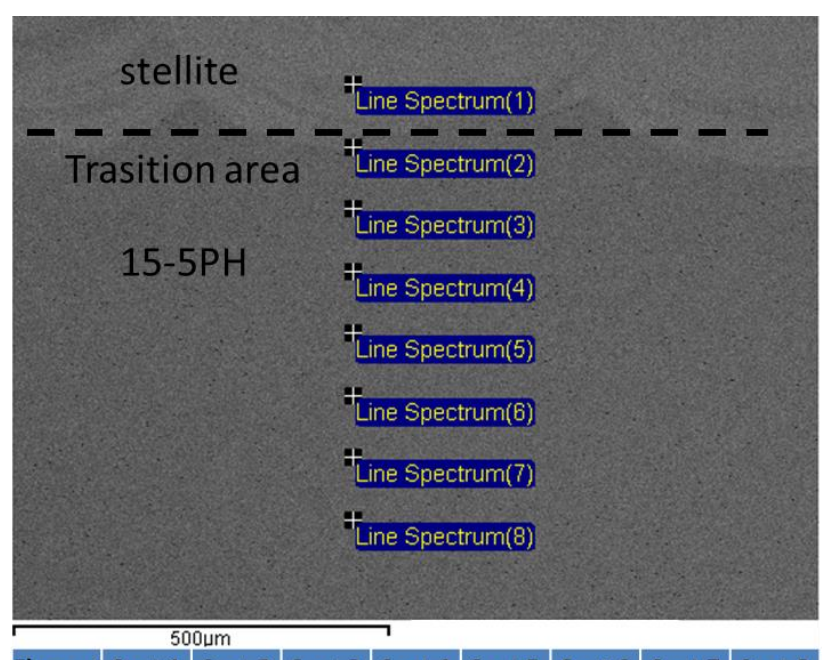

\begin{tabular}{|c|c|c|c|c|c|c|c|c|}
\hline \multicolumn{7}{|c}{$500 \mathrm{um}$} & \multicolumn{2}{c|}{} \\
\hline Element & Spot 1 & Spot 2 & Spot 3 & Spot 4 & Spot 5 & Spot 6 & Spot 7 & Spot 8 \\
\hline $\mathrm{Fe}$ & 48.3 & 59.6 & 75.4 & 75.9 & 75.1 & 76.4 & 75.5 & 74.6 \\
\hline $\mathrm{Cr}$ & 20.6 & 18.4 & 15.6 & 15.5 & 15.8 & 15.5 & 15.7 & 15.7 \\
\hline $\mathrm{Co}$ & 23.3 & 13.8 & & & & & & \\
\hline $\mathrm{Mo}$ & 2.7 & 1.3 & & & & & & \\
\hline $\mathrm{Cu}$ & 1.9 & 2.5 & 3.4 & 3.2 & 3.3 & 2.8 & 3.5 & 4.0 \\
\hline $\mathrm{Si}$ & 0.4 & 0.4 & 0.6 & 0.5 & 0.6 & 0.5 & 0.5 & 0.5 \\
\hline $\mathrm{Ni}$ & 2.8 & 3.4 & 4.2 & 4.1 & 4.4 & 4.0 & 4.0 & 4.4 \\
\hline $\mathrm{Mn}$ & & 0.6 & 0.8 & 0.8 & 0.8 & 0.8 & 0.8 & 0.8 \\
\hline
\end{tabular}

Figure 13. Spot analysis of the element presence in $\mathrm{P}$ transition area in the direction of filling $15-5 \mathrm{PH} \rightarrow$ stellite - the table is in wt. \%

\subsection{MICROSTRUCTURE OF STELLITE}

Stellite structure see Fig. 14 shows a typical cellular structure in melt pools caused by segregation during deposition. Elongated cells are visible and caused by uneven cooling. The height of deposited layers is between 150-200 $\mu \mathrm{m}$.

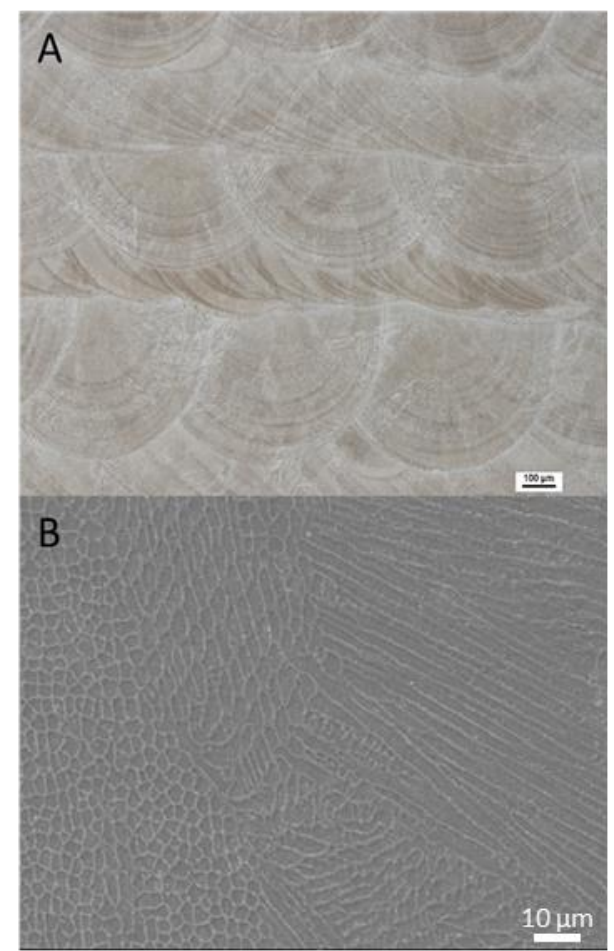

Figure 14. Stellite A) OM, B) SEM 


\section{CONCLUSIONS}

AM deposited a successful build in this work. The build consists of $15-5 \mathrm{PH}$ steel as a similar material to baseplate and stellite, which has a protective function. No defects were detected in the build. The build has good cohesion based on microstructural observations. Elements mixing appeared in transitional areas and is present even after several layers. Mixing could increase the cohesiveness of the transition area, but on the other hand, it can also decrease stellite protective properties. Mechanical properties will be studied in further research.

\section{ACKNOWLEDGMENTS}

This paper was created by project National Centre for Energy No.: TN01000007, financed by the Technology Agency of the Czech Republic

\section{REFERENCES}

[Brazda 2020] Brázda, M., et al. Influence of laser power in direct laser deposition on the proportion of ferrite and austenite in duplex steel SAF2507, Conference Proceedings, 2020. pp. 539-544, ISSN 2694-9296

[Jimenez 2019] Jiménez, M. et al. Additive Manufacturing Technologies: An Overview about 3D Printing Methods and Future Prospects, Complexity, p. 30, 2019.

[Karmakar 2020] Karmakar, D.P. et al. Effect of scan strategy and heat input on the shear strength of laser cladded Stellite 21 layers on AISI H13 tool steel in as-deposited and heat treated conditions, Surface and Coatings Technology, 2020, Vol. 384, ISSN 0257-8972.

[Kiran 2020] Kiran, A. et al. Numerical Simulation Development and Computational Optimization for Directed Energy Deposition Additive Manufacturing Process, Materials, 2020, Vol. 13. , No. 11, ISSN 1996-1944

[Ngo 2018] Ngo, T. D. et al. Additive manufacturing (3D printing): A review of materials, methods, applications and challenges, Composites Part B: Engineering, 2018, Volume 143, pp. 172-196, ISSN 1359-8368

[Salvetr 2020] Salvetr, P. et al. Formation of intermetallics layers in $\mathrm{Ni}$ - $\mathrm{Ti}$ system prepared by direct energy deposition, Manufacturing Technology, 2020, Vol. 19 , No. 4, pp. 674-679, ISSN 1213-2489

[Vavrik 2020] Vavř́ik, J. et al. Residual stress investigation in additively manufactured samples, IOP Conference Series: Materials Science and Engineering, 2020, Vol. 723.

[Yakovlev 2020] Yakovlev, A. et al. Laser-assisted direct manufacturing of functionally graded 3D objects, Surface and Coatings Technology, 2005. , Vol. 190, pp. 15-24, ISSN 0257-8972

[Zhang 2019] Zhang, Ch. et al. Additive manufacturing of functionally graded materials: A review [Journal] // Materials Science and Engineering: A., 2019, Vol. 764, ISSN 0921-5093

\section{CONTACTS}

Ing. Jaroslav Vavrik

COMTES FHT

Prumyslova 995, Dobrany, 334 41, Czech Republic

+420 377197 324, jaroslav.vavrik@comtesfht.cz 